\title{
Pobre efecto de los opioides para el tratamiento de la lumbalgia
}

\author{
Poor effect of opioids to treat low back pain
}

Shaheed, C. y col. JAMA Internal medicine, 2016.

\section{Objetivos}

Evaluar la eficacia de los opioides para tratar el dolor lumbar y la discapacidad; el efecto de los opioides a diferentes dosis; la tolerancia al tratamiento, y la influencia del diseño de estudio "enriquecimiento" sobre los efectos del tratamiento.

\section{Fuentes de datos}

Base de datos electrónicas: Medline, EMBASE, CENTRAL, SINAHL, PsycINFO hasta Septiembre de 2015.

Se realizó además una revisión cruzada en listas de referencias de los ensayos incluidos. No hubo limitación por idioma. No se incluyeron fuentes de literatura gris.

\section{Selección de estudios}

Se incluyeron ensayos clínicos controlados aleatorizados con una población que presentara dolor lumbar inespecífico agudo o crónico (sin importar si las personas presentaban comorbilidades o no), que evaluaran el efecto de opioides solos o combinados con otros analgésicos en comparación con placebo, otros opioides o los mismos opioides a diferentes dosis, para evaluar el efecto sobre el dolor lumbar o la discapacidad.

Los participantes continuaban consumiendo su medicación habitual, incluyendo analgésicos mientras estos no contuvieran opioides, y no se realizaban cambios en los esquemas habituales durante el estudio.

\section{Extracción y análisis de los datos}

La extracción de datos fue llevada a cabo por dos revisores independientes. Los datos relevados fueron el tamaño muestral y el número y localización de los centros donde el estudio se llevó a cabo, el alivio del dolor a través de la escala visual analógica o el puntaje numérico, si la lumbalgia era aguda, subaguda o crónica, el tiempo de seguimiento y si el estudio presentaba enriquecimiento de la muestra o no. Además se tuvo en cuenta si cada estudio era financiado por la industria farmacéutica.

Los datos fueron meta-analizados a través del modelo de efectos mixtos y la fuerza de la evidencia se estimó mediante la metodología GRADE.

\section{Resultados principales}

Los resultados se midieron en la escala del 1 al 100 para medir dolor, y se consideró una reducción clínicamente significativa, al menos 20 puntos de la escala. Los correspondientes a la reducción del dolor se resumen en la tabla 1 . No hubo datos suficientes ni de buena calidad para evaluar el efecto sobre la discapacidad. El enriquecimiento en el diseño de estudio no provocó cambios estadísticamente significativos.

\section{Conclusión}

Los opioides para el tratamiento de la lumbalgia crónica proveen escaso alivio, no clínicamente significativo, y su uso se asocia a un elevado número de efectos adversos.

Fuente de financiamiento: No se especificó fuente de financiamiento o conflicto de intereses.

Tabla 1. Diferencia de medias al final del tratamiento entre opioides y placebo. Se incluyeron estudios con seguimiento de 0 a 12 meses.

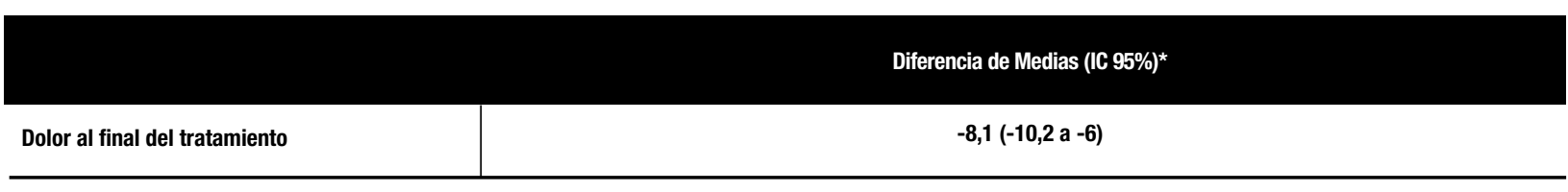

*Los números negativos favorecen a los opioides IC 95\%: Intento de confianza del 95\%. Escala 0 al 100

\section{Comentario}

La lumbalgia es una patología muy relevante en la atención primaria dado que es uno de los principales motivos de consulta, y representa el $40 \%$ de los días laborales perdidos por enfermedad. Ya fue analizado el escaso efecto de otros analgésicos como el paracetamol ${ }^{1}$ para tratar esta patología, con escasa o nula respuesta. En este caso, los opioides no muestran ser la excepción, además de asociarse a efectos adversos. Sin embargo, estos resultados se expresan a nivel poblacional, pudiendo en el consultorio ser diferentes para determinados individuos por razones idiosincráticas. Otro motivo a destacar del estudio es que trata una gama de patologías englobadas con el nombre de "lumbalgia inespecífica", sin diferenciar si el dolor es ligamentoso, muscular, tendinoso u óseo. Por lo tanto, se podría pensar que en caso de ser efectivo ante una de estas etiologías, el hipotético resultado benéfico podría estar diluido por el agregado de otras entidades para las que los opioides no son útiles.

Sería útil realizar nuevos estudios en los que se pudiera definir la causa específica del dolor en la zona lumbar y luego evaluar la eficacia de los distintos tratamientos para aliviarlo.

\section{Conclusiones del comentador}

Dada la baja eficacia demostrada de los opioides sobre el alivio de la lumbalgia llamada "inespecífica" 2 su alta frecuencia de efectos adversos y la incertidumbre sobre sus efectos a largo plazo, sería útil evaluar otras terapias antes de iniciar el tratamiento con estos fármacos, y en caso de considerar hacerlo, explicar al paciente la evidencia sobre sus efectos benéficos y adversos de forma que este pueda ser quien tome la decisión de iniciar esta terapia o no.

Nahuel A. Orcaizaguirre [Servicio de Medicina Familiar y Comunitaria. Hospital Italiano de Buenos Aires. nahuel.orcaizaguirre@hospitalitaliano.org.ar]

Orcaizaguirre NA. Pobre efecto de los opioides para el tratamiento de la lumbalgia. Evid Act Pract Ambul. 2018;21(1):33. Comentado de: Shaheed CA, y col. Efficacy, tolerability, and dose-dependent effects of opioid analgesics for low back pain: A systematic review and meta-analysis. JAMA internal medicine, 2016, vol. 176, no 7, p. 958-968. PMID: 27213267 